\title{
UMA FERRAMENTA DE ANÁLISE DA ACESSIBILIDADE EM INSTITUIÇÕES DE LONGA PERMANÊNCIA PARA IDOSOS
}

\section{AN ACCESSIBILITY ANALYSIS TOOL IN LONG-TERM CARE FACILITIES FOR THE ELDERLY}

\author{
Emmanuel Sá Resende Pedroso ${ }^{1}, \mathrm{Me}$. \\ Isabella Cristina Aquino de $\mathrm{Souza}^{2}$, graduanda \\ Marla Oliveira Souza ${ }^{3}$, graduanda \\ Quézia Santos Damasceno ${ }^{4}$, graduanda \\ (1) Universidade Federal de Juiz de Fora \\ e-mail: emmanuel.pedroso@arquitetura.ufjf.br \\ (2) Universidade Federal de Juiz de Fora \\ e-mail: bella.aquinos@gmail.com \\ (3) Universidade Federal de Juiz de Fora \\ e-mail:marla.oliveira@arquitetura.ufjf.br \\ (4) Universidade Federal de Juiz de Fora \\ e-mail: quezia.damasceno2014@arquitetura.ufjf.br
}

Acessibilidade, Instituição de Longa Permanência Para Idosos, Análise

Diante do envelhecimento da população brasileira, a habitação coletiva de caráter Institucional tem sido constantemente procurada, mas muitas vezes se mostra inadequada para as demandas apresentadas por seus residentes. O objetivo deste estudo é apresentar, uma proposta de ferramenta de análise da acessibilidade em Instituições de Longa Permanência para Idosos.

Accessibility, Institution of Long Stay for the Elderly, Analysis

Faced with the aging of the Brazilian population, collective housing of an institutional character has been constantly sought, but often proves to be inadequate for the demands presented by its residents. The objective of this study is to present, a proposal of tool of analysis of accessibility in Institutions of Long Stay for the Elderly. 


\section{$16^{\circ}$ \\ ERGODESIGN USIHC CINAHPA}

\section{Introdução}

A população mundial passa por um processo de envelhecimento e no Brasil a situação não é diferente. Assim, as cidades brasileiras devem se preparar para atender a essa população cada vez maior, em suas respectivas necessidades. Nesse contexto, existem demandas no tocante à habitação destinada à pessoa idosa, especialmente a habitação coletiva de caráter institucional, denominadas no Brasil como Instituições de Longa Permanência Para idosos - ILPI's. O objetivo geral deste estudo é apresentar, em síntese, uma proposta de ferramenta de análise da acessibilidade, a ser aplicada em ILPI's. Em sua estrutura, este artigo traz a fundamentação teórica da pesquisa, a metodologia utilizada, o contexto das ILPI's na cidade na qual o instrumento será aplicado - Juiz de Fora, estado de Minas Gerais, Brasil - a apresentação do instrumento de análise e as considerações finais, bem como todas as referências bibliográficas e agradecimentos.

\section{Fundamentação teórica}

Este estudo aborda temas como a acessibilidade e as ILPI's. De acordo com a Política Nacional do Idoso (Lei no 8842 , de 1994) e o Estatuto do idoso (Lei ${ }^{\circ} 10741$, de 2003), as pessoas com idade igual ou superior a 60 anos são consideradas idosas [BRASIL, 1994, 2003]. O processo de envelhecimento ainda é uma questão pouco discutida na área de arquitetura e urbanismo, apesar de ser um tema de grande relevância. Essa fase da vida traz consigo diversas transformações, tanto físicas quanto mentais, sendo um exemplo as perdas apresentadas junto aos sentidos: visão, audição, tato, paladar e olfato [FREITAS et al., 2006]. Diante disso, o ambiente construído, por sua vez, precisa continuar oferecendo suporte às atividades realizadas pelo indivíduo quando este alcança a velhice. Para tanto, a acessibilidade é essencial.

Um espaço acessível, pois, pode ser definido, de acordo com a NBR 9050/15 como a

$$
\text { [...] possibilidade e condição de alcance, }
$$

$16^{\circ}$ Ergodesign - Congresso Internacional de Ergonomia e Usabilidade de Interfaces Humano Tecnológica: Produto, Informações Ambientes Construídos e Transporte

$16^{\circ}$ USIHC - Congresso Internacional de Ergonomia e Usabilidade de Interfaces Humano Computador

CINAHPA | 2017 - Congresso Internacional de Ambientes Hipermídia para Aprendizagem.

\begin{abstract}
percepção e entendimento para utilização, com segurança e autonomia, dos espaços, mobiliários, equipamentos urbanos, edificações, transportes, informação e comunicação, inclusive seus sistemas e tecnologias, bem como outros serviços e instalações abertos ao público, de uso público ou privado de uso coletivo, tanto na zona urbana como na rural, por pessoa com deficiência ou mobilidade reduzida [ABNT, 2015, p 2].
\end{abstract}

A promoção da acessibilidade está vinculada diretamente à superação de barreiras, definidas pelo Estatuto da Pessoa com Deficiência (Lei ${ }^{\circ}$ 13146, de 2015) como "[...] qualquer entrave ou obstáculo, atitude ou comportamento que limite ou impeça a participação social da pessoa [...]" [BRASIL, 2015, p 08]. Ainda de acordo com Brasil [2015], as barreiras são classificadas em barreiras urbanísticas; barreiras arquitetônicas; barreiras nos transportes; barreiras nas comunicações e na informação; barreiras atitudinais; e barreiras tecnológicas.

Relacionados à acessibilidade, existe o conceito de acessibilidade espacial. A acessibilidade espacial, segundo Dischinger, Ely e Piardi [2012], acontece quando o local permite que o usuário perceba sua função, organização e relações espaciais, participando das atividades realizadas naquele espaço com o devido conforto, segurança e independência. Dischinger, Ely e Piardi [2012] apontam quatro componentes relacionados à esse conceito, sendo eles a orientação espacial; a comunicação, entre pessoas ou delas com equipamentos; o deslocamento; e o uso.

Este estudo direciona o conceito de acessibilidade espacial para um dos principais equipamentos urbanos voltados para a terceira idade no Brasil: as ILPI's. De acordo com a Portaria $\mathrm{n}^{\mathbf{0}} \mathbf{7 3}$, de 2001, as ILPI's, que se enquadram no caso do Atendimento Integral Institucional, são locais onde

o atendimento é prestado em uma instituição asilar, prioritariamente à idosos sem famílias, em situação de vulnerabilidade, oferecendolhes serviços nas áreas social, psicológica, médica, de fisioterapia, de terapia ocupacional, de enfermagem, de odontologia
Realização:

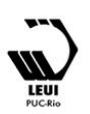




\section{$16^{\circ}$ \\ ERGODESIGN USIHC CINAHPA}

e outras atividades específicas para este segmento social [BRASIL, 2001, p 52].

Ainda segundo Brasil [2001], as ILPI's se dividem em três modalidades: (1) instituição destinada a idosos independentes; (2) instituição destinada a idosos dependentes e independentes; e (3) instituição destinada a idosos dependentes.

Portanto, é possível observar que a questão da qualidade de vida do idoso está diretamente relacionada à acessibilidade e que, para alcançá-la, diversos fatores devem ser analisados e estudados no ambiente construído - neste caso, nas ILPI's.

\section{Metodologia}

Para a elaboração da ferramenta, foi adotada a técnica da documentação indireta, que possui como objetivo [...] recolher informações prévias sobre o campo de interesse" [MARCONI; LAKATOS, 2003, p 174]. Neste estudo, essa técnica permitiu a revisão bibliográfica a respeito dos temas acessibilidade e ILPI's. A estrutura do instrumento de análise da acessibilidade, foi feita a partir da adoção do checklist, sendo esta uma técnica desenvolvida

\footnotetext{
por meio de uma lista de questões ou sugestões relacionadas [...] usa a lista de perguntas ou afirmações para guiar o desenvolvimento de ideias inteiramente novas ou se concentrar em áreas específicas de "ideias". A checklist pode assumir qualquer forma e ter qualquer tamanho [HISRICH; PETERS; SHEPHERD, 2014, p 79].
}

Dessa forma, foi criada uma ferramenta para a análise da acessibilidade em ILPI's, a ser aplicada na cidade de Juiz de Fora.

\section{Contexto: a cidade de Juiz de Fora}

Juiz de Fora é um município brasileiro localizado na região da Zona da Mata, no Estado de Minas Gerais, Brasil. Sua população atual é estimada em 559.636 habitantes sendo que, desse total, 69.094 são idosos [IBGE, 2016]. Logo, o município possui demandas expressivas com relação à sua população idosa, dentre as quais estão as ILPI's. $16^{\circ}$ Ergodesign - Congresso Internacional de Ergonomia e Usabilidade de Interfaces Humano Tecnológica: Produto, Informações Ambientes Construídos e Transporte

$16^{\circ}$ USIHC - Congresso Internacional de Ergonomia e Usabilidade de Interfaces Humano Computador

CINAHPA | 2017 - Congresso Internacional de Ambientes Hipermídia para Aprendizagem.

A cidade possui 23 ILPI's, sendo três filantrópicas; dezenove particulares; e uma mista (particular/filantrópica) [PJF, 2017]. Não existem instituições públicas no município, ou seja, onde os serviços são ofertados pelo Poder Público.

\section{A ferramenta de análise da acessibilidade}

A estrutura da ferramenta de análise teve como referência o modelo apresentado por Dischinger, Ely e Piardi (2012) no livro "Promovendo acessibilidade espacial nos edifícios públicos: Programa de Acessibilidade às Pessoas com Deficiência ou Mobilidade Reduzida nas Edificações de Uso Público". Mesmo destinado à análise da acessibilidade em outro contexto (edifícios públicos), o instrumento proposto pelas autoras forneceu a base da formatação da planilha aqui apresentada, especialmente no que diz respeito à disposição dos itens a serem avaliados em linhas e dos pontos de análise em colunas.

A elaboração do instrumento se deu através da concepção de duas planilhas: (1) planilha de aplicação; e (2) planilha de tratamento dos dados. Ambas as planilhas devem ser utilizadas por uma equipe de pesquisadores. É recomendado que a mesma equipe atue nas duas planilhas, de maneira a favorecer o estabelecimento de relações entre a pesquisa de campo e os dados alcançados. O tempo estimado para a aplicação da ferramenta - das planilhas de aplicação e de tratamento dos dados em cada ILPI é de cerca de três meses.

Na planilha de aplicação estão listados itens - de acordo com as normas, leis e conceitos relacionados à acessibilidade - reunidos em cada um dos setores e ambientes - estes, estabelecidos a partir da Portaria $n^{\circ} 73$, de 2001, e Resolução de Diretoria Colegiada n ${ }^{\circ} 283$ [BRASIL, 2001]

[ANVISA, 2005]. Essa planilha deve ser aplicada em todos os ambientes que compõem a ILPI. Dessa forma, um dos primeiros produtos alcançados será a verificação do atendimento, por parte da instituição, aos espaços previstos na Portaria $n^{\circ} 73$, de 2001 e na Resolução de Diretoria Colegiada $n^{\circ} 283$ [BRASIL, 2001] [ANVISA, 2005]. A planilha completa possui dezenove páginas, no formato A4. É apresentado a seguir um 


\section{$16^{\circ}$ \\ ERGODESIGN USIHC CINAHPA}

esquema gráfico referente à estrutura da planilha (Figura 01).
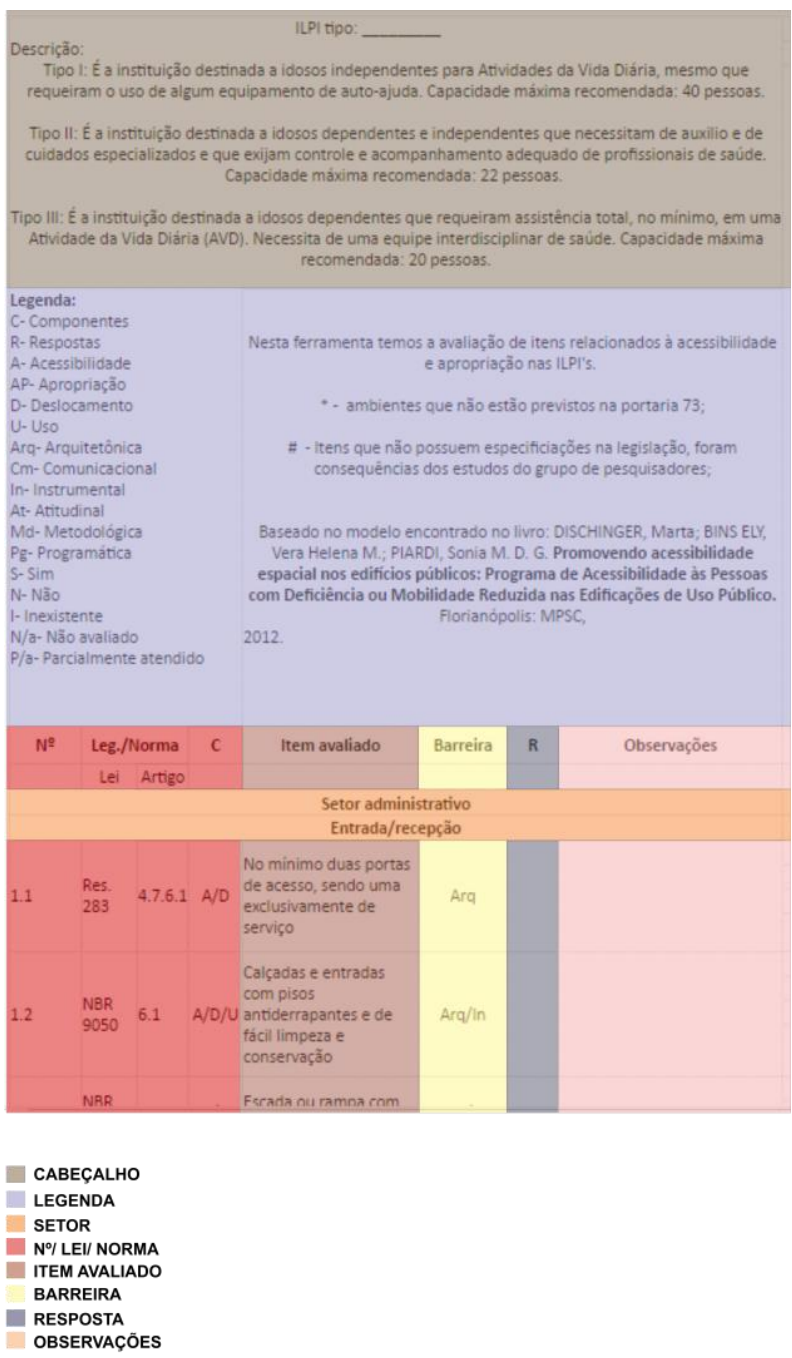

Figura 01 - Esquema geral da ferramenta - Fonte: arquivo próprio.

O cabeçalho da ferramenta traz informações a respeito da ILPI onde o trabalho será realizado, juntamente com o nome do pesquisador, local, data e hora da aplicação. Além disso, identifica-se a modalidade na qual a Instituição se encaixa, de acordo com as descrições encontradas na Portaria $\mathrm{n}^{\mathrm{o}} 73$, de 2001 - tipo (I), destinada a idosos independentes; tipo (II), voltada para idosos dependentes e independentes; e tipo (III), direcionada a idosos dependentes [BRASIL, 2001].

Na segunda parte da planilha, existe uma legenda $16^{\circ}$ Ergodesign - Congresso Internacional de Ergonomia e Usabilidade de Interfaces Humano Tecnológica: Produto, Informações Ambientes Construídos e Transporte

$16^{\circ}$ USIHC - Congresso Internacional de Ergonomia e Usabilidade de Interfaces Humano Computador

CINAHPA | 2017 - Congresso Internacional de Ambientes Hipermídia para Aprendizagem. para que seja possível a compreensão das siglas utilizadas, sendo elas "C", para os componentes da acessibilidade espacial (D - deslocamento; $\mathrm{O}$ orientação; C - comunicação e U - uso); "B”, para os tipos de barreiras (Urb - urbanísticas; Arq arquitetônicas; Tra - nos transportes; Com - nas comunicações e informação; e At - atitudinais); e "R", para as respostas ( $\mathrm{S}-\operatorname{sim} ; \mathrm{N}$ - não; $\mathrm{I}$ inexistente; N/a - não avaliado e P/a parcialmente atendido). Posteriormente, tem-se a terceira parte da planilha, na qual estão os setores e seus ambientes, acompanhados pelos itens a serem analisados. Em cada linha, há um item numerado, com a legislação ou norma a ele relacionado, $o$ componente da acessibilidade espacial no qual se encaixa, a caracterização do tipo de barreira, a resposta acerca do item verificado e as devidas observações.

A inserção dos itens teve como meta atender a exigências da normatização e da legislação vigentes, e de agentes que acompanham a atuação das ILPI's, como Ministério Público, da Vigilância Sanitária e do Corpo de Bombeiros. Alguns itens não encontram suporte em normas e leis e, sim, nos conceitos abordados na fundamentação teórica do trabalho.

Os setores e ambientes estabelecidos foram: (1) íntimo, com sala de atividades individuais, banheiros individuais e quartos coletivos $(1,2$ ou 4 dormitórios); (2) serviço, com copa/cozinha, lavanderia, ambulatório, almoxarifado e depósito, banheiro funcionários e depósito de lixo; (3) social, com sala de atividades coletivas, sala de convivência (TV/jogos), refeitório, espaço interreligioso, banheiros coletivos e guarda-roupas de uso coletivo; (4) administrativo, com entrada/recepção, sala direção/reunião e sala de apoio individual e sócio familiar; e (5) circulação esta, analisada separadamente, haja vista sua relação com o deambular do idoso e possíveis quedas.

O tratamento dos dados, a ser realizado por meio de uma segunda planilha, engloba a reunião dos resultados por setores e ambientes, permitindo uma análise tanto geral, quanto específica da acessibilidade na ILPI (Figura 02). 


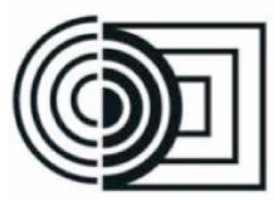

$16^{\circ}$ Ergodesign - Congresso Internacional de Ergonomia e Usabilidade de Interfaces Humano Tecnológica: Produto, Informações Ambientes Construídos e Transporte

$16^{\circ}$ USIHC - Congresso Internacional de Ergonomia e Usabilidade de Interfaces Humano Computador

CINAHPA | 2017 - Congresso Internacional de Ambientes Hipermídia para Aprendizagem.

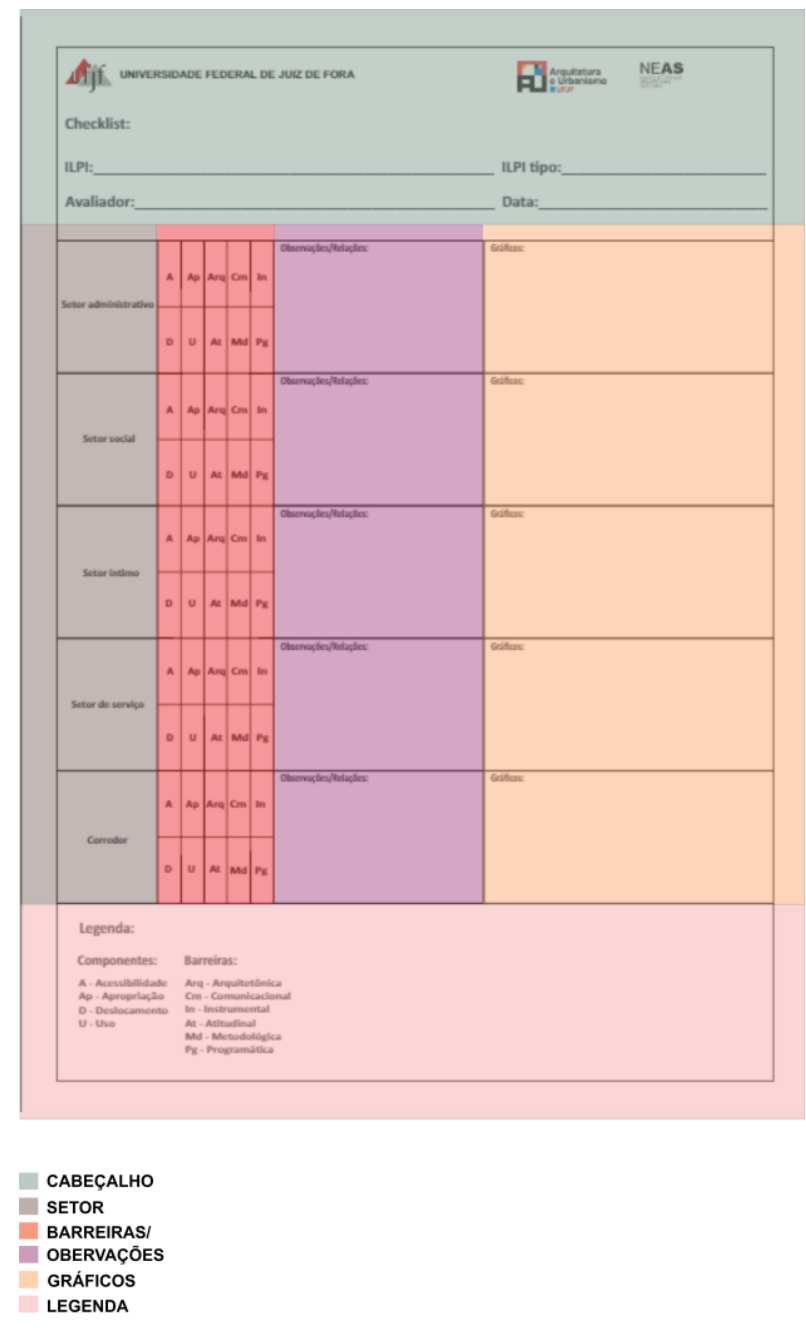

Figura 02 - Planilha de tratamento dos dados. Fonte: arquivo próprio.

A planilha de tratamento dos dados possui formato A3 e é composta por três partes. Na primeira parte, há um cabeçalho, com informações acerca do pesquisador, da ILPI e da data de preenchimento do documento. Na segunda parte, está reunida a análise realizada, disposta em quatro colunas setores; somatório das avaliações (positiva, regular ou negativa) dos componentes da acessibilidade espacial; observações e possíveis relações constatadas entre os componentes da acessibilidade espacial e os tipos de barreiras avaliados na coluna anterior e os itens verificados no setor; e gráficos dos setores com seus ambientes, focalizados nos componentes da acessibilidade espacial e nos tipos de barreiras. Na terceira parte, está a legenda adotada na planilha.
O instrumento deve ser acompanhado por um levantamento fotográfico da instituição estudada. Em tempo, cabe aqui atentar para o fato de que a ferramenta de análise da acessibilidade em ILPI's não constitui um instrumento fechado, sendo necessária a sua revisão periódica, a fim de otimizá-la e atualizá-la. Além disso, por ser elaborada para ser aplicada nas ILPI's da cidade de Juiz de Fora, ela possui questões de legislação relacionadas ao município e ao estado de Minas Gerais. Dessa forma, sua utilização em outras cidades e estados brasileiros exige a sua revisão.

\section{Considerações finais}

As ILPI's, dentre suas várias necessidades, precisam de um assessoramento técnico em acessibilidade. A obtenção de um ambiente seguro para o idoso e adequados às suas expectativas passa, necessariamente, por esse conceito. A cidade de Juiz de Fora ilustra o contexto brasileiro, ao possuir uma população idosa expressiva e apresentar demandas referentes à moradia coletiva institucional destinada a esse público - no tocante tanto à orientação técnica junto às instituições existentes, quanto à criação de novos equipamentos urbanos com essa finalidade.

A ferramenta de análise da acessibilidade em ILPI's, aqui apresentada em síntese, uma vez aplicada, pode gerar contribuições para esses dois pontos. Ao permitir a identificação das barreiras existentes e a obtenção de um diagnóstico acerca das condições de deslocamento, orientação, comunicação e uso do ambiente pela pessoa idosa, em cada instituição, esse instrumento, além de assessorar diretamente a ILPI estudada, se coloca como uma possível referência a ser adotada em novos projetos. A utilização da ferramenta aqui proposta pode favorecer a autonomia e independência dos idosos residentes em ILPI's, contribuindo de maneira significativa para a melhoria de sua qualidade de vida.

\section{BIBLIOGRAFIA}

ANVISA. Resolução RDC n⿳ 283, de 26 de setembro de 2005. Aprova o Regulamento Técnico que define normas de funcionamento para
Realização:

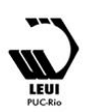


$16^{\circ}$ USIHC - Congresso Internacional de Ergonomia e Usabilidade de Interfaces Humano Computador

CINAHPA | 2017 - Congresso Internacional de Ambientes Hipermídia para Aprendizagem.

as Instituições de Longa Permanência para Idosos. Diário Oficial da União; Poder Executivo, Brasília, DF, 27 set. 2005.

\section{ASSOCIAÇÃO BRASILEIRA DE NORMAS} TÉCNICAS - ABNT. NBR 9050: Acessibilidade a edificações, mobiliário, espaços e equipamentos urbanos. Associação Brasileira de Normas Técnicas, Rio de Janeiro, 2015.

BRASIL. Leis. Lei ${ }^{\circ} 8842$ jan. 1994. Dispõe sobre a política nacional do idoso, cria o Conselho Nacional do Idoso e dá outras providências. Diário Oficial [da] República Federativa do Brasil, Poder Executivo, Brasília, DF, 5 jan. 1994.

Leis. Lei $\mathrm{n}^{\circ} 10741$ out. 2003. Dispõe sobre o Estatuto do Idoso e dá outras providências. Diário Oficial [da] República Federativa do Brasil, Brasília, DF, 3 out. 2003.

Leis. Lei $\mathrm{n}^{\circ} 13146$ jul. 2015. Institui a Lei Brasileira de Inclusão da Pessoa com Deficiência (Estatuto da Pessoa com Deficiência). Diário Oficial [da] República Federativa do Brasil, Brasília, DF, 6 jul. 2015.

Portaria $\mathbf{n}^{\mathbf{0}}$ 73, de 10 de maio de 2001. Estabelece normas de funcionamento de serviços de atenção ao idoso no Brasil, nas modalidades previstas na Política Nacional do Idoso, e aos desafios que o crescimento demográfico impõe ao país. Diário Oficial da União, Poder Executivo, Brasília, DF, 10 maio 2001.

Ministério do Planejamento, orçamento e gestão. Manual de Perícia Oficial em Saúde do Servidor Público Federal. Esplanada dos Ministérios; Brasília DF, 2010.

CAMBIAGHI, S. Desenho Universal - métodos e técnicas para arquitetos e urbanistas. São Paulo: Ed. Senac São Paulo, 2007.

COHEN, R.; DUARTE, C. R. S. Subsídios metodológicos na construção de uma "acessibilidade plena": a produção da identidade e da subjetividade de pessoas com deficiência. Edição Especial 03, 2013, 19p.
DISCHINGER, M.; ELY, V. H. M. B.; PIARDI, S. M. D. G. Promovendo acessibilidade espacial nos edifícios públicos: Programa de Acessibilidade às Pessoas com Deficiência ou Mobilidade Reduzida nas Edificações de Uso Público. Florianópolis: MPSC, 2012. Disponível em: <http://www.proderg.com.br/artigos cientificos/Manual\%20-\%20Acessibilidade\%20em \%20Edif\%C3\%ADcios\%20P\%C3\%BAblicos.pdf> Acesso em: 19 mar. 2017.

FREITAS, E. V.; PY, L.; CANÇADO, F. A. X.; DOLL, J.; GORZONI, M. L. Tratado de Geriatria e Gerontologia. 2. ed. Rio de Janeiro: Editora Guanabara Koogan, 2006.

HISRICH, R. D.; PETERS M. P.; SHEPHERD D. A. Empreendedorismo - $9^{a}$ edição. Porto Alegre: AMGH Editora Ltda, 2014.

INSTITUTO BRASILEIRO DE GEOGRAFIA E ESTATÍSTICA - IBGE. Expectativa de vida no Brasil, 2002. Disponível em: <http://www.ibge. gov.br>. Acesso em: 15 fev. 2017.

IBGE. Cidades, Juiz de Fora, 2016.

Disponível em: < http://www.ibge.gov.br>. Acesso em: 15 fev. 2017.

PREFEITURA DE JUIZ DE FORA - PJF. Secretaria de Saúde. Departamento de Vigilância Sanitária. ILPI's - Particulares e Filantrópicas de Juiz de Fora. Juiz de Fora, 2017, 2 p.

RHEINGANTZ, P. A. et al. Observando a Qualidade do Lugar: procedimentos para a avaliação pós-ocupação. Rio de Janeiro: Coleção PROARQ/FAU/UFRJ, 2009. Disponível em: $<$ http://www.gae.fau.ufrj.br/assets/obs_a_qua_luga r.pdf> Acesso em: 19 mar. 2017.

\section{Agradecimentos}

É importante agradecer à Pró-Reitoria de Graduação da Universidade Federal de Juiz de Fora pelo apoio ao Projeto "Acessibilidade em Instituições de Longa Permanência para Idosos", no qual foi realizado o estudo aqui apresentado.
Realização:

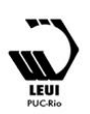

